\title{
Urgences
}

\section{Sortie d'URGENCES numéro deux}

\section{Jean Cossette}

Numéro 2, 3e trimestre 1981

URI : https://id.erudit.org/iderudit/025019ar

DOI : https://doi.org/10.7202/025019ar

Aller au sommaire du numéro

Éditeur(s)

Urgences

ISSN

0226-9554 (imprimé)

1927-3924 (numérique)

Découvrir la revue

Citer ce document

Cossette, J. (1981). Sortie d'URGENCES numéro deux. Urgences, (2), 3-4.

https://doi.org/10.7202/025019ar

Ce document est protégé par la loi sur le droit d'auteur. L'utilisation des services d'Érudit (y compris la reproduction) est assujettie à sa politique d'utilisation que vous pouvez consulter en ligne.

https://apropos.erudit.org/fr/usagers/politique-dutilisation/
Cet article est diffusé et préservé par Érudit.

Érudit est un consortium interuniversitaire sans but lucratif composé de l'Université de Montréal, l'Université Laval et l'Université du Québec à Montréal. Il a pour mission la promotion et la valorisation de la recherche. https://www.erudit.org/fr/ 
Sortie d'URGENCES numéro deux.

Qu'on le veuille ou non, arrivés au point de mire et conscients tout à fait que l'imaginaire peut sauver de l'uniformité du quotidien, on prend tous un jour la sortie d'urgence. Nous vous en proposons une ici par le biais de ce numéro deux. Loin de vouloir affirmer que c'est la seule sortie efficace en ce domaine, nous n'en demeurons pas moins convaincus que plus il existera de sorties, plus les chances de parvenir au "nirvãna" littéraire seront bonnes. La condition préalable: s'ouvrir le coeur et l'esprit. La magie des mots se chargera du reste. Le voyage vous intéresse-t-il? Alors suivez-nous et...

...vous aurez l'occasion de vous attarder sur les ilots poétiques de Réjean Dubé, cultivés d'instants fugitifs où l'oeil s'arrête, photographié lui-même et à son insu par des clichés impressionnistes; vous aurez accès à la vision acerbe et effilée, aux confins de la caricature, de Danielle BérubéLeblond, s'insinuant dans un monde particulier, jadis chevaleresque, maintenant olympique à défaut d'être olympien. Sonia Angueloua vous donnera le pouls d'un pays qui bat dans la tête et le souvenir qui vacille à la renverse de l'indicible espoir des retrouvailles. La nostalgie démesurée jusqu'à la déraison d'être. Avec Réjean Mc Kinnon, nous ferons un pas dans le monde "à réfléchir", où le réel s'embourbe dans l'irréel, où tout s'estompe bientôt dans une dimension élargie et "enlargie" empreinte de fabuleux.

Grâce à Jean-Claude Clavet, nous prendrons la douce conscience de l'être en devenir et en devenu, étreint par la lucidité du moment présent. Puis, Michel Lévesque nous fera part des attentes implacables qui s'imprègnent au-delà même de l'objet, qui s'insinuent à force de temps dans les viscères existentielles. Huguette Marquis nous donnera accès à une séquence tirée de la vie d'une femme, issue d'un quotidien 
navrant mais qui se métamorphosera en une sorte de catharsis, de libération sous condition. L'inspiration glanée au fil des jours par Hélène Carle témoignera d'une attente sage et de l'expression d'un vécu lucide. Suivra Charles-Aimé Poirier avec ses "propos et confidences d'un Vieux Maître d'École", où l'émergence du passé attise la fonction analytique sur un certain milieu.

$\mathrm{Au}$ côté de James Paulin, nous aborderons l'histoire et l'espace mêlés à la conscience comme un lien frêle qui surgit du sang pour aller dégeler l'hiver. La poésie suave et fruitée de Lise Lessard nous jouera ses orchestrations d'images aux couleurs de nacre et à l'accent exotique. Avec Alain Blanchet, nous assisterons à l'affrontement dans les dédales contemporains de notre civilisation en transit. Pour enchaîner, quelques parenthèses que je vous livre et qui seront ce que vous y mettrez. Enfin, Richard Lévesque, avec des textes engageants qui vont bien plus loin que les images redondantes de l'écran-télé et qui assomment "littéralement" l'indifférence de notre éloignement. dire!

Bonne traversée, chers lecteurs, dans ces urgences de

Jean Cossette pour le Comité de Direction 